\title{
Crisis Management : based on the Five Hypotheses proposed by Jack Welch
}

\author{
Zhao Jianying \\ Shanxi Academy of Governance, 030006 \\ (E-mail:zjy97828@163.com)
}

\begin{abstract}
With the wide spread and application of the Internet, information and communication technology, an increasingly complex information age has arrived . How governments can manage public crisis more scientific and more effective, turn crises into opportunities, pass through a dangerous crisis safely in the information age has become the most pressing matter of every government now .

General Electric Company, Chairman and CEO Jack Welch in his book Winning proposed the Five Hypotheses of crisis management. This article is written from the Five Hypotheses of crisis management based on Management Science, Media Science and Public Relations. This article believe that the public crisis management in China still can not meet the requirements of the information age, and there is not a mature, stable and viable public crisis management system. So, this thesis rebuild the measures and the work steps of the government in each stage of crisis management. The conclusions are that government should prepare for the worst at the beginning of public crisis management, be prepared for the emergence of some people and things which may happen in the process, be information disclosure, to frank and open to the public and the media. At last, the most important thing is confidential in overcoming the public crisis.
\end{abstract}

Keywords: Crisis , public crisis management, the Five Hypotheses of Crisis Management

\section{Introduction}

Since the 1990s, communications technology and computers, in particular the rapid development and wide application of Internet technology, mark that the information age has arrived. As Owen E. Hughes said, "the changes that occurred in recent years are more than any other period of the 20th century". How to survive this change, make development through crisis has become the concern of various organizations. So a public crisis management theory which can response the public crisis more scientific and effective will undoubtedly be the government's choice.

\subsection{Foreign Research}

The theory of crisis management as an independent subject first appeared in the 1960s. Western academia, government, NGO and other types of organizations attached considerable importance to it after it appeared, and they established specialized research institutions. Since the mid 1990s, the accelerating process of globalization has made the forms of the crisis increasingly diversified. So, the crisis management study in the West has also made a new development.

Overall, the status of foreign research on crisis management mainly expressed in the following areas: research trends from qualitative research to quantitative research; research methods from a single subject research to multi-disciplinary research; the scope of the study from the military field, natural disasters extended to the economic, political, social and other fields. At the same time, the vertical depth also develops: computers and networks as research tools become more and more important .

\subsection{Domestic research}

The idea of China's crisis management has a long history. Before the Qin Dynasty, crisis management thinking such as "be prepared for danger in times of peace" appeared. However, compared with foreign countries, our country's crisis management, whether the theory or practice, are relatively late. But as crises in 
recent years frequently happen in China, governments, universities, enterprises and specialized agencies have established crisis management teams, and have made some progress.

The results of the domestic crisis management are expressed in the following areas: the general theory of crisis management has been mature; government's public crisis management has made significant progress; the government's role in crisis management changed from the Government Center to Multi-center; crisis management changed from the "non-legal mode" to "legal model"; crisis management changed from focusing on the rescue to steering the whole process; refinement of crisis management are refined, interdisciplinary research appeared, and a large number of research results come out.

Although some progress has been made, our crisis management is still lagging behind the West, and there are still a lot of problems such as think much of macro, hardware, heavy remedy and theory, but think little of minor, software, prevention and the practice.

\section{The assumptions of the theory of public crisis management and the Five Hypotheses of crisis management}

\subsection{The meaning of public crisis management}

The crisis is a sudden emergency event, which may make the organization suffer a serious loss or face the threat of serious losses. It has the following characteristics: sudden; two sides; derivative; uncertainty; focus; frequently, and so on.

As revealed by the crisis features, "Every crisis contains the roots of failure, but also breeds the seeds of success". Public crisis management refers that to avoid or mitigate the severe damage and threat brought by the public crisis, the government learn, develop and implement a series of management measures and strategies in a planned way, including the avoid of crisis, control of crisis, solve of crisis and revival of crisis. It's a comprehensive management process. Broadly speaking, any government measures and behaviors to prevent and defuse crisis are public crisis management.

\subsection{The Five Hypotheses of the crisis management}

The Five Hypotheses of crisis management are put forward in the tenth chapter "crisis management - must not sit still" of Jack Welch book winning. It was originally proposed the company's crisis management, however, after it came out, people found that this theory is applicable to any organization's crisis management. Of course, it's also applicable to the government's public crisis management.

Jack Welch reckons that as long as people exist, the crisis is inevitable. So he suggested to consider the Five Hypotheses in dealing with the crisis. First, assuming that the crisis itself are worse than the outside appearance and what we expected. Most of the time the crisis will last longer, spread to a larger scale, and are more difficult to control. Therefore, at the beginning of the crisis we should prepare the worst, and have to fix it. Second, assuming that the world does not exist any secret, and eventually everybody will know all the truth of the matter. The news which we try to blockade will eventually leak out and will definitely distort. The only way is making the truth known to the public by yourself. If you do not do this, it will be done by others, but then things will become more difficult. Third, assuming that your own organization will be described in the most hostile way, including the measures you did . Fourth, assuming that people will be changed. If you do not pay the price, then a crisis will not really end. This is not easy or a pleasant thing, but unfortunately, if not, the organization can not continue to move forward. Fifth, assuming that your organization will survive from the crisis, even become stronger by experiencing the test. As that sentence said "a positive attitude and confidence are important force to overcome the difficulties. So we must be full of confidence because confidence is more important than gold and currency."

\section{3.the problems and drawbacks of the public crisis management of our government based on the Five Hypotheses}

Because the study of crisis management in China started late, mature crisis management mechanism has not been established. Inevitably there are some problems which affect the effect of public crisis management. These problems 
and drawbacks are shown in:

\subsection{Wrong understanding of crisis}

Government neglect the cause of crisis, or fail to fully identify all of the incentives which produce the crisis, underestimate the human factors or natural factors (environmental factors) of crisis development, fail to effectively avoid the occurrence of the crisis, kill the crisis in the bud.

There is a deviation on the difficulty level of the public crisis. Two situations are included: one is underestimation the difficulty level. Another situation is to think the crisis is too complex to solve. So people no longer try to find a solution. Moreover, the first case is the majority .

There is an inadequate understanding of the object related to the crisis. Because of the increasingly close contact of modern society, public crisis is not only related to the direct stakeholders, but also to other people which are not directly affected. Some government think that the crisis has been resolved, and thus no longer take the initiative to understand the public's feedback resulting but in fact the public crisis can not be fully solved.

\section{2 "Obscurantism" deeply entrenched}

Many government decision makers has a serious tendency of individual heroism. The implementation of "obscurantism" after the crisis keep people from the truth because they worried that people who knew the truth would damage the government and their own interests. What is more, officers delay in reporting, cheat, or fail to report the fact and the result. The result is not only failing to avoid social panic, but also leading to greater social panic. The two is that the public crisis management is the government internal affair, and unrelated to the outside world, the media, and the public. One of the most important performance is not good at using media. Due to China's Internet, micro-blog and other new media in recent years are developed, the government lacks the experience of using media to handle public crisis. Governments are very unresponsive after crisis, doesn't take kindly to media and make good use of mass media. Just as a proverb says," when the truth is putting on the boots, rumors have traveled all over the world". This " bureaucracy"is not conducive to the correct use of social forces to deal with the crisis.

The decision making system has many serious drawbacks. Long term's "inaccurate" habits and the existence of the" one-vote veto" phenomenon make public crisis decision making system not scientific. At the same time, as a result of our country long-term feudalism influence, bureaucracy is more outstanding, patriarchal decision making style remains. Decision making is still strong emotional. So it is difficult to avoid personal will or prejudice and bring the decision making error.

In addition, there is ignorance of the decision making responsibility. The grass-roots governments lack mobility, flexibility. Coordination problems are also very serious.

\subsection{Contradiction to change}

In the public crisis management process, in order to maintain local interest or departmental interests, some local governments or departments exist serious local and department protectionism, lacking awareness of the overall concept, resisting changes, resulting in the crisis worsen, which not only make these interests not being protected, but also the government's overall interests damaged.

Another meaning of resistance to change is in the crisis prevention process. Governments can not reform according to the development of the time, but take a stick in the mud, follow the beaten track attitude, cause the public crisis can not be solved reasonably .

\subsection{Being pessimistic to the result}

In the process of dealing with public crisis, some officers lack of confidence in the government recovering from the crisis. So in the resolution of the crisis, they are mutual buck-passing, negativity. Thus governments delay the best opportunity of solving crisis .

\section{The public crisis measures and suggestions based on the Five Hypotheses}

\subsection{The crisis prevention measures}

Prevention is the first line of defense in public crisis management. In the prevention stage, make a reasonable precaution, take some corresponding preventive measures can reduce or avoid the loss brought by public crisis.

$4.1 .1 \mathrm{We}$ need to make relevant laws, regulations and rules. Perfect laws and regulations system is the important conditions to avoid public crisis.

4.1.2Build perfect public crisis plan. "Public crisis plan is the basis of government behavior 
when public crisis occurs. If public crisis plan is perfect, the public crisis can be solved smoothly and efficiently. Public crisis plan should be integrity (comprehensive), maneuverability, foreseeing, initiative, scientific, and so on. In particular, when the government is formulating public crisis plan, he must prepare for the worst.

4.1.3 Information collection and analysis. Mastering the accurate, comprehensive information is of great significance. The government through collecting and analysis related information make science public crisis forecast, establishing a scientific crisis warning system makes the government take actions before the crisis as soon as possible.

4.1.4 Basic resource reserve. Resources reserve is an important guarantee of public crisis management. The government establishing adequate supplies before the crisis, such as information communication, make resources handy, can mobilize all reserve after crisis. At this point, after"5.12" earthquake, various governments have already formed consensus.

4.1.5 Dealing with the public crisis through professional training, improving the officer's professional accomplishment ability can be accomplished by training, lectures, and also by printing, distributing of public crisis management manual to achieve. If government is conditional, it can also organize public crisis simulation exercises.

\subsection{Measures at the crisis outbreak stage}

The outbreak of the crisis is a its development climax stage. During this period, the occurrence of public crisis is irreversible.

4.2.1 Give information timely, accurate release and open actively. After the crisis information communication is considered as the basis of coordinating all actions. Do a good job of information dissemination, secure personnel and the public's right to know the truth, and inform the public. Taking the initiative to open the truth can avoid the rumors, avoid government have greater losses. At the same time, improve the government's control ability on new media and the ability to deal with the media, improve the government 's media literacy, and use media to serve the public crisis management.

4.2.2 Start of public crisis plan, establish public crisis management mechanism, command and coordinate the relevant personnel, departments to dissolve the crisis. In dealing with public crisis, governments must be timely, active, professional and seize the fundament, at the same time should also maintain the junior branches's appropriate flexibility and initiative. 4.2.3 Scientific decision making, democratic participation and implementation powerful are necessary. The government should establish a scientific view of crisis in decision making, such as democratic participation, information disclosure and other. In addition, the implementation of the decision making, coordination mechanism and supervision mechanism should be strengthened, too. Adopting the scientific decision making method and drawing lessons from the successful experience at all times and in all countries in history is also necessary in solving public crisis .

\subsection{Measures at crisis transition phase}

During this period, the public crisis has not so serious as crisis outbreak stage, but still exists the risk of recurrence, and the secondary crisis caused by the outbreak of the crisis can also be sparked, so governments still need to be vigilant. At this stage, the main task is to consolidate results of the last stage, to prevent secondary crisis, and to ensure the society translate from crisis to normal mode smoothly.

4.3.1 Establish crisis consciousness and hardship consciousness, prevent" recurrence of an old illness". Although this period mainly crisis has been solved basically, but the mind cannot drop one's guard, it must be " taut nerve" in order to completely solve the crisis.

4.3.2 Great attention to detail and eliminate the vestiges, eliminate the root causes of public crisis fundamentally. Details determine success or failure, so the governments must start from details, and solve small problems. The eradication of public crisis's soil is the fundamental way of public crisis management.

\subsection{Measures at the last stage of public crisis}

The last stage of public crisis is the important link in the process of crisis management. At this stage, the mainly task is the restoration and reconstruction of property, facilities, order, psychological recovery, sums up the successful experiences and the lessons of failure.

4.4.1 Restoration and reconstruction. The restoration and reconstruction not only refers to the property, compensation and repair of facilities, restoring the normal order of the society, the more important thing is social public psychological comfort, which enabling 
them to establish confidence in the government.

4.4.2. Sum up experience and lessons. When he was summing up the "SARS" experience, Premier Wen Jiabao said:" a nation in the disaster can learn more things than usual." For a nation that, a government too. Based on the comprehensive analysis of the crisis, sum up experience, put forward a government to improve and make the necessary organizational change.

In particular, the public crisis management's stages in the actual operation process cannot be divided so clearly as the theory division. It is often mixed together. Therefore, the countermeasures must mix each other.

\section{Conclusion}

When a crisis comes, it does not mean absolute ly impaired or absolutely negative, it is a choic e. If your choice is right, you can jump to the a new step, but if the wrong choice, you will get a great harm and loss. In this article, we use the Five Hypotheses of public crisis management purposed by Jack Welch to analysis the shortco mings on Chinese government dealing with the public crisis, and we purposed four stages on $h$ ow to deal with the crisis properly as the follo wing: prevention stage, outbreak stage, transiti on stages, restoration stage. What's regretful is that we did not use this conclusion to do positi vism study, and it will be our further study.

\section{Reference}

[1] Welch, J. Winning CITIC Publishing House ,2010. (In Chinese)

[2]Yimin Zhang. Corporate crisis management. Science Press,2004. (In Chinese)

[3]Robert Heath. Crisis management CITIC Publishing House.. 2004. (In Chinese)

[4]Lan Xue, Qiang Zhang Zhong Kaibin. Crisis management - the challengesfacing China in transition. Tsinghua University Press, 2003. (In Chinese)

[5]Dewu Zhu .Crisis management: the choice facing emergencies Guangdong Economic Press, 2002. (In Chinese)

[6]Guowen Ye . Crisis management: experience of the West and China's task. The city management 2003. (In Chinese)

[7]Shaoguang Wang . Angang.Hu Yuanzhu.Ding. Social instability behind of the economic prosperity. strategy and management,2002. (In Chinese)

[8]Regester Michaek Larkin Judy .Risk Issues and Crisis Management Peking University Press, 2005. (In Chinese)

[9]Jingxin Lin. Network crisis management: the Web2.0 era corporate crisissolution Jinan University press,2009. (In Chinese) 